\title{
Push Enteroscopy Guided Removal of a Sharp Foreign Body from the Midjejunum in a Child
}

\author{
Sridhar Sundaram¹ Suprabhat Giri ${ }^{\circledR}$ Biswaranjan Patra ${ }^{1}$ Harish Darak ${ }^{1}$ Shobna Bhatia ${ }^{1}$ \\ ${ }^{1}$ Department of Gastroenterology, King Edward Memorial Hospital, \\ Seth Gordhandas Sunderdas Medical College, India

\begin{abstract}
Address for correspondence Suprabhat Giri, MBBS, MD, Department of Gastroenterology, King Edward Memorial Hospital, Seth Gordhandas Sunderdas Medical College, Ward 32A, 9th Floor, New OPD Building, Acharya Donde Marg, Parel, Mumbai 400012, Maharashtra, India (e-mail: supg19167@gmail.com).
\end{abstract}

\begin{abstract}
Keywords

- enteroscopy

- foreign body

- pediatric endoscopy

Background The majority of foreign bodies entering the small intestine are passed spontaneously. However, in case of a sharp object, its removal is an urgency due to a higher risk of intestinal perforation, and endoscopic intervention is an appropriate management strategy as surgery is associated with greater morbidity. Although enteroscopy is the standard practice for the removal of a foreign body in the small intestine, gastroduodenoscopy may be used for small intestinal foreign body removal. Case Presentation We describe here the case of a 21-month-old child in whom a $5-\mathrm{cm}$, sharp-pointed nail in the midjejunum was removed successfully by a gastroduodenoscopy. This case highlights the difficulties in the removal of a sharp foreign body in a pediatric patient and the use of push enteroscopy.

Conclusion Gastroduodenoscopy can be used for the removal of a foreign body in the small intestine in pediatric population in a resource-limited setup by performing push enteroscopy.
\end{abstract}

\section{Introduction}

Foreign body ingestion and impaction account for a large number of emergency room visits. While most adults have food bolus or bone impaction, children and patients with psychiatric illness often present with nonfood foreign body ingestion. A large proportion of patients pass out spontaneously; however, endoscopic intervention may be required in $20 \%$ of patients, with need for surgery in a selected few. ${ }^{1}$ Retrieval of foreign bodies from the esophagus and stomach is commonly performed, but small bowel foreign bodies are rarely retrieved endoscopically. We report the safe endoscopic removal of a sharp nail from the midjejunum in a 21-month-old child.

\section{Case Report}

A 21-month-old boy presented to the emergency department with a history of ingestion of a nail. X-ray of the abdomen performed 4 hours after ingestion revealed a nail of approximately $5 \mathrm{~cm}$ size lying in the stomach ( $\boldsymbol{- \text { Fig. }} \mathbf{1}$ ). Endoscopy was performed under general anesthesia approximately 6 hours after ingestion of the foreign body. An adult gastroscope was used for the procedure. Despite the sharp nature of the foreign body, a hood could not be used as it was difficult to pass it through the throat of the child. The nail was not found in the stomach. However, under fluoroscopy guidance, enteroscopy was performed using an adult gastroscope. The nail was found to be impacted in the midjejunum ( - Fig. 2a, b). The nail was dislodged using alligator forceps and grasped carefully with the hexagonal snare. The nail had to be maneuvered across the various bends ensuring that the sharp end did not pierce the walls of the bowel. For retrieval from the esophagus, the nail was aligned vertically by grasping the head end with the snare and keeping the sharp end away from the scope to avoid trauma. - Fig. 3 shows the nail after removal. The child was stable and had no complications postprocedure. 


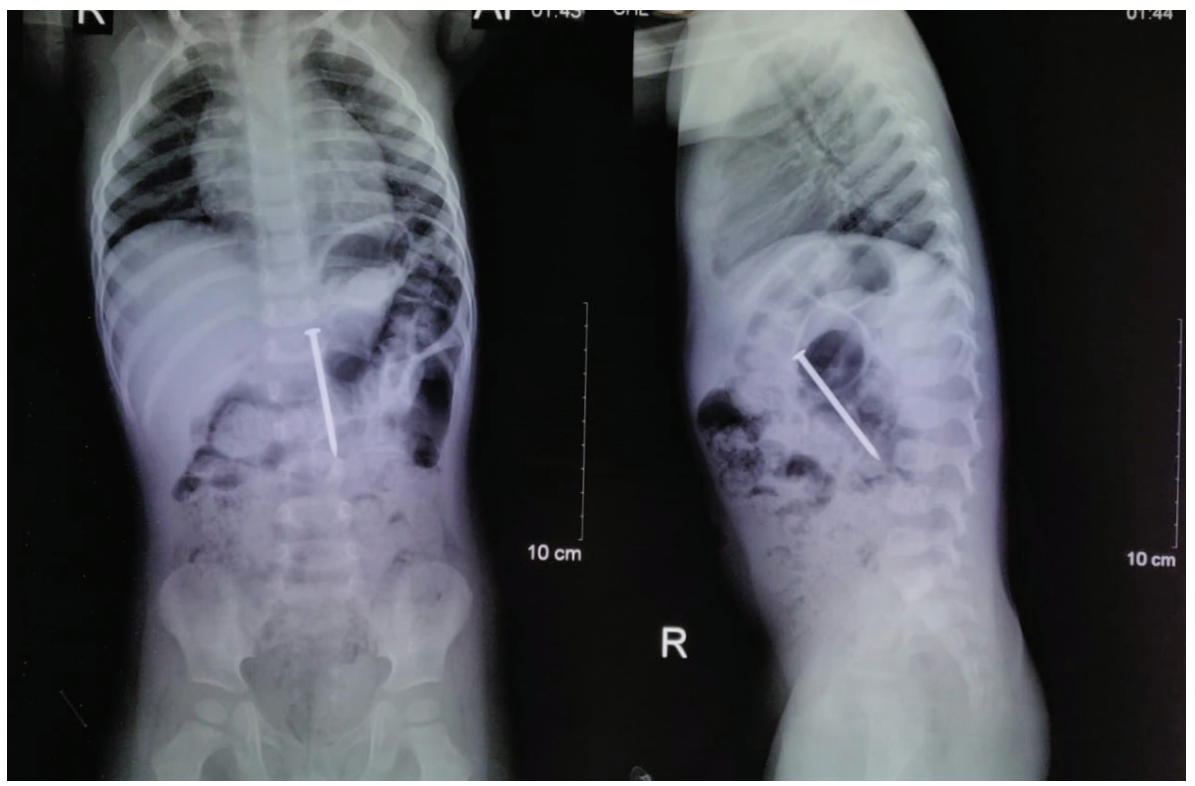

Fig. 1 X-ray of the abdomen showing a nail of approximately $5 \mathrm{~cm}$ likely in the stomach.

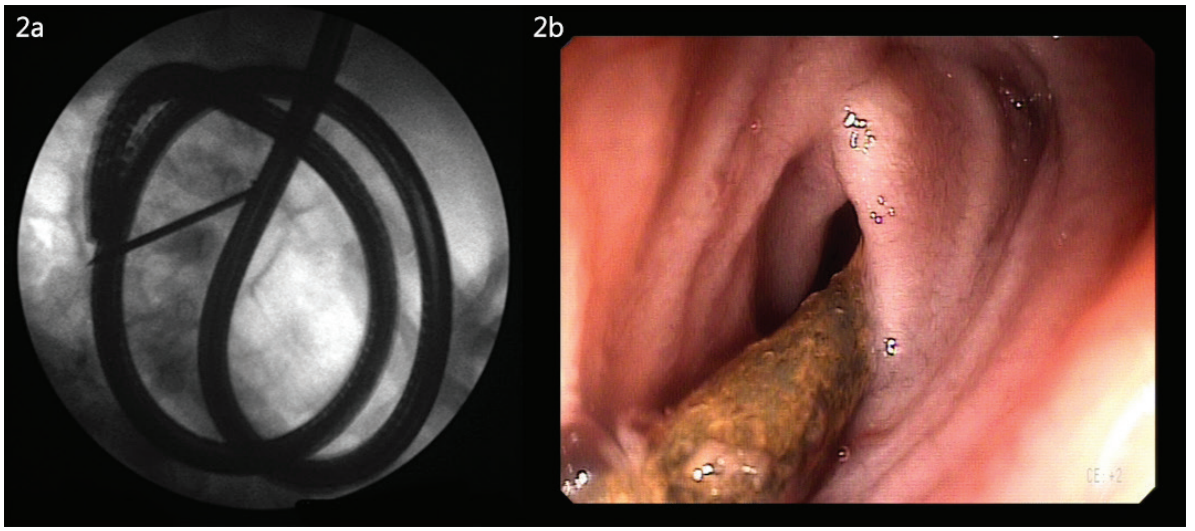

Fig. 2 (a) Fluoroscopic image of the scope while retrieving the nail from the jejunum. (b) Endoscopic image of the nail impacted in the jejunum.

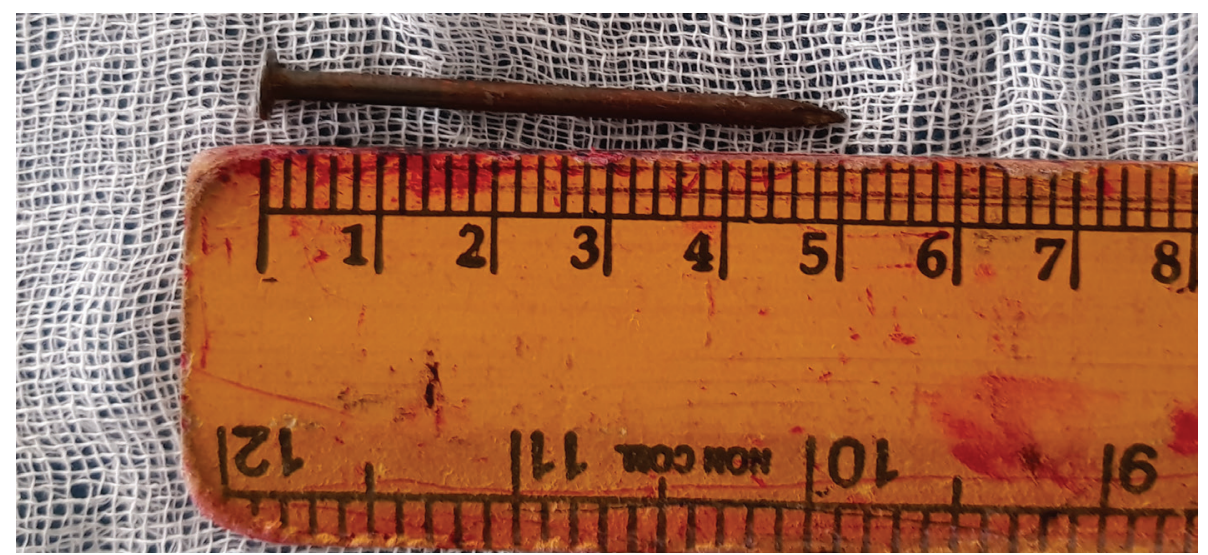

Fig. 3 Retrieved nail of $5 \mathrm{~cm}$ in size.

\section{Discussion}

Foreign bodies can get impacted in the esophagus, pass into the stomach or further into the small intestine. The American Society for Gastrointestinal Endoscopy recommends urgent endoscopic removal ( $<24$ hours) of sharp foreign bodies from the stomach. On the other hand, endoscopic removal of foreign bodies in the esophagus should be performed on an emergency basis ( $<6$ hours). ${ }^{2}$ ESGE (European Society of Gastrointestinal Endoscopy) and ESPGHAN (European Society 
for Paediatric Gastroenterology Hepatology and Nutrition), on the other hand, recommend emergent removal of sharp foreign bodies in the stomach or proximal duodenum in children, considering the increased risk of complications in up to $35 \%$ cases. $^{3}$ An abdominal X-ray revealed the nail in the stomach in our patient, and hence endoscopy was planned. We used an adult gastroscope since the working channel in a pediatric gastroscope would not allow passage of adult alligator forceps and snare. Pediatric endoscopic intervention is often challenging, needing general anesthesia, with the choice of scope and accessories depending on the weight and age of the child. Use of a double-balloon enteroscope for the removal of an impacted nail of $1.5 \mathrm{~cm}$ in a 19-year-old male patient has been previously reported. ${ }^{4}$ Only a few case reports of endoscopic removal of small bowel foreign bodies were found in literature review. ${ }^{5,6}$ No reports are present on the removal of foreign body from the small bowel in children. Use of an overtube has been reported for the safe retrieval of sharp foreign bodies in adults. ${ }^{7}$ However, use of a hood or overtube was not feasible in our case.

The challenges in our patient included the large size and nature of the foreign body, age and weight of the patient, the site of impaction of the foreign body, and inability to use a hood or overtube in the patient for safety. Careful assessment of benefit versus risk in the endoscopic removal of foreign bodies from the small bowel is needed, especially in pediatric patients.

\section{Funding}

None.

\section{Conflict of Interest}

None.

\section{References}

1 Sugawa C, Ono H, Taleb M, Lucas CE. Endoscopic management of foreign bodies in the upper gastrointestinal tract: a review. World J Gastrointest Endosc 2014;6(10):475-481

2 Ikenberry SO, Jue TL, Anderson MA, et al; ASGE Standards of Practice Committee. Management of ingested foreign bodies and food impactions. Gastrointest Endosc 2011;73(6): 1085-1091

3 Tringali A, Thomson M, Dumonceau JM, et al. Pediatric gastrointestinal endoscopy: European Society of Gastrointestinal Endoscopy (ESGE) and European Society for Paediatric Gastroenterology Hepatology and Nutrition (ESPGHAN) Guideline Executive summary. Endoscopy 2017;49(1):83-91

4 Kim DJ, Sim MK, Lee SW, Lee TH. Successful removal of a screw nail in the jejunum using double-balloon enteroscopy. Clin Endosc 2015;48(5):444-446

5 Neumann H, Fry LC, Rickes S, Jurczok C, Malfertheiner P, Mönkemüller K. A 'double-balloon enteroscopy worth the money': endoscopic removal of a coin lodged in the small bowel. Dig Dis 2008;26(4):388-389

6 Chu YC, Yeh YH, Yang CC, Chen CH, Yueh SK, Mo LR. A new indication for double-balloon enteroscopy: removal of migrated metal stents through a Roux-en-Y anastomosis. Endoscopy 2007;39(Suppl 1):E148

7 Ofosu A, Ramai D, Reddy M. Overtube-assisted foreign body removal: a review of endoscopic management and case illustration. Cureus 2017;9(9):e1730 